\title{
Associated clinical abnormalities among patients with Turner syndrome
}

\author{
(D) Suna Kilinc, ${ }^{1}$ (D) Metin Yildiz, ${ }^{2}$ (D) Ayla Guven ${ }^{2,3}$ \\ ${ }^{1}$ Department of Pediatric Endocrinology, University of Health Sciences, Istanbul Bagcilar Training and Research Hospital, Istanbul, Turkey \\ ${ }^{2}$ Department of Pediatric, Goztepe Training and Research Hospital, Istanbul, Turkey \\ ${ }^{3}$ Department of Pediatric Endocrinology, University ofHealth Sciences, Istanbul Zeynep Kamil Women and Children Hospital, Istanbul, Turkey
}

\begin{abstract}
OBJECTIVE: The early diagnosis of Turner syndrome (TS) is often difficult because of the various clinical features. This study aimed to investigate clinical features and identify associated abnormalities in a group of patients with TS.

METHODS: Retrospective data of presenting clinical features collected from the medical records of the 37 patients with TS. All patients were examined for associated clinical abnormalities.

RESULTS: Mean age at diagnosis was $9.3 \pm 4.1$ years. The main reason for referral was short stature and/or delayed puberty. All of the patients had at least one dysmorphic sign. Skeletal system abnormalities (57\%) were the most common associated abnormality, which was followed by gastrointestinal system problems (40\%). Cardiac defects occurred in $32 \%$. Urinary system abnormalities occurred in $27 \%$. Dermatological problems were detected in $32 \%$ of the patients. The pathology of the hearing was found in $19 \%$. Autoimmune thyroid disease was detected in $24 \%$ of the patients, and celiac disease was detected in $5.4 \%$ of the patients.
\end{abstract}

CONCLUSION: Phenotypic variability often leads to a delay in the diagnosis of TS. Early diagnosis can initiate effective management in patients with TS.

Keywords: Associated abnormalities; clinical features; diagnosis; Turner syndrome.

Cite this article as: Kilinc S, Yildiz M, Guven A. Associated clinical abnormalities among patients with Turner syndrome. North Clin Istanb 2020;7(3):226-230.

T urner syndrome (TS), which occurs due to the partial or complete mutation of the $\mathrm{X}$ chromosome, is one of the most common genetic disorder [1]. In addition to gonadal dysgenesis and short stature, which are classical features of the syndrome, the long term analysis of patients also proves unwanted complications associated with congenital heart, kidney and skeletal anomalies, thus affecting their living standards in a negative manner [2,3]. Early diagnosis and proper management of associated abnormalities will have a positive effect on the improvement of patient's height, as well as on their quality of life enhancement. Here, we analyzed the clini- cal manifestation and frequency of associated abnormalities of TS patients, which will provide some evidence for a more comprehensive understanding of the clinical diagnosis of TS.

\section{MATERIALS AND METHODS}

Thirty-seven subjects diagnosed with TS were included in this study. The data of the reason for referral, age at diagnosis, auxological parameters (from birth to last follow-up visit), presence of dysmorphic features and clinical phenotypes were noted from the medical records. Besides

Received: November 26, 2018 Accepted: August 01, 2019 Online: April 14, 2020

Correspondence: Dr. Suna KILINC. Saglik Bilimleri Universitesi, Istanbul Bagcilar Egitim ve Arastirma Hastanesi, Cocuk Endokrinoloji Klinigi, Merkez Mahallesi, 6. Sokak, 34100 Bagcilar, Istanbul, Turkey.

Tel: +90 2124404000 e-mail: sunahancili@hotmail.com

(c) Copyright 2020 by Istanbul Provincial Directorate of Health - Available online at www.northclinist.com 
these, all patients were re-evaluated for associated clinical abnormalities. The cardiac evaluation was performed by transthoracic echocardiography. Renal findings based on a urinary ultrasound examination. Gastrointestinal system abnormalities evaluated by testing alanine aminotransferase (ALT) and aspartate aminotransferase (AST) and abdominal ultrasonography. All patients were examined by an ophthalmologist, otolaryngologist, dermatologist and orthodontist to confirm the presence of any abnormal features. An audiogram was performed to all patients. Skeletal system and bone abnormalities evaluated by a radiologist. The patients were also evaluated for autoimmune diseases, such as Hashimoto thyroiditis and celiac disease. For the diagnosis of celiac disease, the histological data of patients serologically biopsied with the presence of anti-endomysial antibody (anti-EMA) were considered. Written informed consent was obtained from the patients and/or parents of each patient, and this study was approved by the local ethics committee of our hospital.

\section{Statistical Analysis}

Data were analyzed using the program NCSS 2007 (Number Cruncher Statistical System, Kaysville, Utah, USA). Descriptive statistics (mean, standard deviation, median value) in the case of normally distributed variables were used.

\section{RESULTS}

\section{Auxological Data and Diagnosis of TS}

The mean age at the time of this study was $14.6 \pm 4.8$ (range was 4.2-23.6) years. Among all 37 patients, 45,X karyotype was the most frequent (57\%), followed by the mosaicism (11\%) and other chromosome abnormalities. The main reason for referral was short stature and/or delayed puberty. The baseline height of patients was $118.5 \pm 14.5 \mathrm{~cm}$, and the height-SDS (standard deviation score) was $-3.31 \pm 0.98$. A delay in growth was detected at the time of diagnosis with a discordant predictable adult height compared to genetic potential (predicted adult height-SDS $-2.66 \pm 1.16$ vs target height-SDS $-0.71 \pm 0.68)$. The age of patients at first visit ranged from $0.09-17.1$ years. Mean age at diagnosis was $9.3 \pm 4.1$ years. The mean duration between the appeal to our clinic and the diagnosis was $0.58 \pm 0.9$ years. In $8 \%$ of the patients, the diagnosis of TS was revealed in the first years of life, in $35 \%$ of the patients at the age of $1-10$

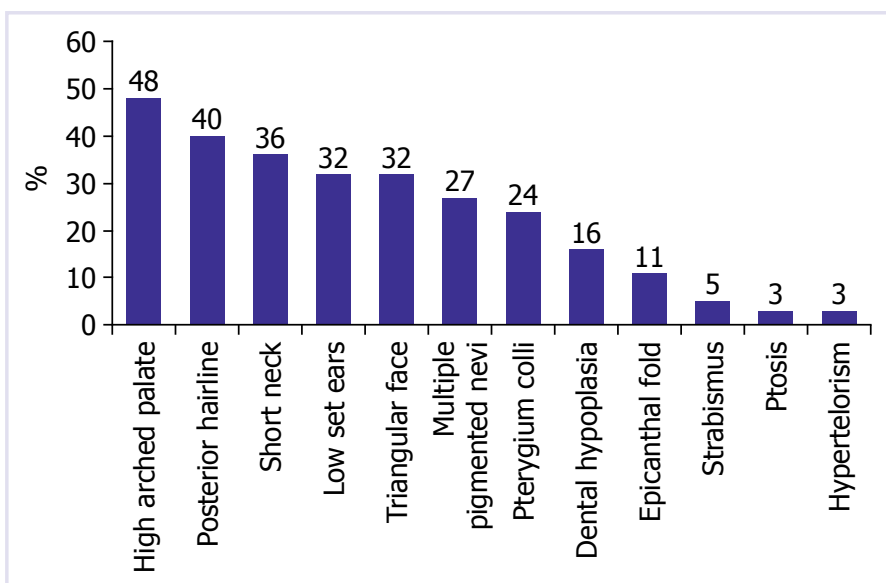

FIGURE 1. The main craniofacial dysmorphic signs observed in our patients.

years old, and in $57 \%$ of the patients at the age of $10-18$ years old. When the diagnosis was made in the first year of life $(n=3)$, the most common clinical sign was lymphedema. Short stature was found in all the patients diagnosed after the age of 10 years $(n=21)$ and frequently associated with delayed puberty (19 out of 21 patients). Only in two patients with mosaic karyotype, incomplete spontaneous puberty occurred.

\section{Clinical Characteristics and Associated Abnormalities}

Besides short stature and delayed puberty, all of the patients had at least one dysmorphic sign. The characteristics of craniofacial dysmorphic signs are listed in order of frequency of occurrence in Figure 1. Except these craniofacial dysmorphic signs, the other dysmorphic findings were wide-spaced nipple (18\%) and nail hypoplasia (8\%). Skeletal system abnormalities were found to be predominant $(57 \%)$ as compared to other system abnormalities. Scoliosis and cubitus valgus were the most common findings in $10(27 \%)$ and eight (21\%) patients, respectively, followed by short fourth metacarpal bone in four (10\%) patients. Gastrointestinal system problems (40\%) were the second most common associated abnormalities. Mainly, it was hepatosteatosis $(n=10)$ and elevated transaminase levels $(n=5)$. Cardiac anomalies $(32 \%)$ were seen less frequently, which commonly showed bicuspid aortic valve $(n=4)$, aortic stenosis $(n=3)$, aorta coarctation $(n=2)$, mitral regurgitation $(n=1)$, mitral valve prolapse $(n=1)$ and aortic insufficiency $(n=1)$. On urinary system ultrasonography, $27 \%$ of the patients had urinary tract malformations, including horseshoe kidney $(n=3)$, duplication of the collecting system $(n=3)$, renal 
TABLE 1. Clinical characteristics and associated problems in patients with TS

\begin{tabular}{|c|c|c|c|c|c|}
\hline Clinical characteristics & Cardiovascular & Renal & Gastrointestinal & Skeletal system & Autoimmune disease \\
\hline Delayed puberty & Aortic stenosis & Double collecting & Elevated liver & Short $4^{\text {th }}$ & Celiac disease \\
\hline Low posterior hairline & Mitral regurgitation & Kidney hypoplasia & & Kyphosis & \\
\hline Cubitus valgus & Mitral valve prolapse & Ectopic kidney & & & \\
\hline \multicolumn{6}{|l|}{ Pigmented nevus } \\
\hline \multicolumn{6}{|l|}{ Pterygium colli } \\
\hline \multicolumn{6}{|l|}{ Widely spaced nipples } \\
\hline \multicolumn{6}{|l|}{ Hearing loss } \\
\hline \multicolumn{6}{|l|}{ Ptosis } \\
\hline Vitiligo & & & & & \\
\hline
\end{tabular}

hypoplasia $(n=2)$, renal ectopia $(n=1)$ and malrotated kidney $(n=1)$. Dermatological problems were detected in $32 \%$ of the patients. Multiple pigmented nevi $(n=10)$, vitiligo $(n=1)$ and keloid $(n=1)$ were the established dermatological problems. The pathology of the hearing was found in 19\%. Hearing loss (three patients had conductive, two patients had sensory-neural type hearing loss) was the most common finding, followed by recurrent otitis media $(n=2)$. When patients were examined for autoimmune diseases, thyroid autoantibodies were positive in eight (24\%) patients, and all of them had hypothyroidism. In two patients, thyroid autoantibodies were negative, but subclinical hypothyroidism was detected with a normal fT4 and elevated TSH. Anti-EMA positivity was detected in four of $37(10 \%)$ patients. Histological features of the duodenal biopsy were compatible with celiac disease in two (5\%) patients. Celiac antibody positivity was found in four (11\%) patients. Clinical characteristics and associated problems in patients with TS are shown in Table 1.

\section{DISCUSSION}

The diagnosis of TS is usually delayed in all populations, with up to $38 \%$ of the patients diagnosed in adulthood in a series $[4,5]$. This study indicates that, although most patients with TS are diagnosed in childhood, a significant proportion of patients are diagnosed in adolescence are more likely because of the most part of referrals of patients with the delayed growth and/or absence of pubertal sings are in advanced age. The age at diagnosis for the patients in this study was similar to that found in the literature and was consistent with a recent study that has suggested a decline in the age at diagnosis over the last few years [6].

The presentation of TS varies throughout a patient's life [7]. The most common complaints at the first presentation for TS are short stature and delay in puberty. In $91 \%$ of our cases, short stature was the presenting complaint and in line with the literature, the majority of our patients had short stature and/or delay in puberty. Dysmorphic signs are important findings in TS that makes it noticeable [8]. Dysmorphic findings of TS include high arched palate, low set ear, epicanthal fold, webbed neck, and low posterior hairline, broad chest with widely spaced nipples, cubitus valgus, and multi-pigmented nevi. Figure 1 provides the associated craniofacial dysmorphic findings of our patients in order of frequency of occurrence.

TS is also associated with a wide range of congenital malformations affecting nearly every organ system 
[9-11]. These malformations and the associated morbidity explain the part of the increased mortality in TS [3]. Congenital cardiovascular defects that are the most important life-threatening pathology in these patients affects $26-50 \%$ of the individuals with TS $[12,13]$. The frequency of cardiac abnormalities in our patients is in accordance with previous reports. Congenital renal anomalies are also more common among TS patients with a prevalence of $24-42 \%$, which is approximately 9 -fold higher than the general population [1]. In our study, renal abnormality rate was $27 \%$, and these were mostly horseshoe kidney and double collecting duct system, a finding which is consistent with the literature. Women with TS have an increased risk of developing chronic liver disease, including liver cirrhosis [3]. In our study, hepatosteatosis and elevated transaminases were more common. Although celiac disease occurs with an increased frequency (6.4\%) in the TS population [14], in our patients, biopsy-proven celiac disease was detected in a few patients.

Skeletal system anomalies are extensive in TS patients as well [15]. The majority of patients with TS require examined for many aspects, such as from structural bone defects for kyphosis, scoliosis, short neck and body proportion. The frequency of skeletal system anomalies was half of them in our study and scoliosis was the most common pathology. Because of the high incidence, in a recent guideline for the care of girls and women with TS, it is recommended clinical evaluation for scoliosis every six months during growth hormone therapy or otherwise annually until growth is completed [16].

It is also described as a higher occurrence of skin pathologies in patients with TS. Pigmented nevi, pilomatricoma, vitiligo, psoriasis, alopecia and keloid formation after surgical intervention are the most reported skin problems in TS patients [17-19]. Although the prevalence of pigmented nevi (15-64\%) increased in patients with TS, it was found that other skin problems did not increase compared to the general population [20,21]. In our cohort, a dermatologist evaluated all of the $37 \mathrm{pa}$ tients. Pigmented nevus was the most frequent pathology. Therapy with growth hormones may trigger melanocyte growth, but it has been shown neither to increase the number of nevi nor to trigger malignant transformation $[22,23]$. Since hearing problems are common in patients with TS (30-90\%), a formal audiometric evaluation is recommended every five years regardless of initial age at diagnosis $[16,24]$. In this study, hearing loss was lower than the published studies [24]. The lower prevalence of hearing loss in our study may be due to the small number of subjects. Thyroid dysfunction and autoimmune thyroid disease have also been found to be more prevalent in patients with TS [1]. Our series confirm this with onethird of patients suffered from hypothyroidism, either overt or subclinical. Antibody positivity was also similar. In a large cohort, Radetti et al. [25] studied 478 females with TS, mean age of 15.5 years, and found that $22.2 \%$ patients had positive thyroid autoantibodies, of which $27 \%(29 / 106)$ patients were hypothyroid and 3\% patients were thyrotoxic. Among this small cohort, hyperthyroidism was not detected in any patients.

In conclusion, phenotypic variability and the lack of firm diagnostic criteria often lead to a delay in diagnosis of TS. Dermatologists, orthopedists, dentists, ophthalmologists and cardiologists should evaluate all TS patients for associated anomalies. A hearing test should be performed to all patients as well. Early diagnosis will provide timely treatment that includes adequate medical, psychological and social assistance to patients with TS and their families.

Ethics Committee Approval: Bagcilar Training and Research Hospital Clinical Research Ethics Committee granted approval for this study (date: 11.07.2017, number: 2017-591).

Conflict of Interest: No conflict of interest was declared by the authors.

Financial Disclosure: The authors declared that this study has received no financial support.

Authorship Contributions: Concept - SK, AG; Design - SK, AG; Supervision - SK, AG; Materials - SK, MY, AG; Data collection and/ or processing - SK, MY, AG; Analysis and/or interpretation - SK, MY, AG; Literature review - SK, AG; Writing - SK, AG; Critical review SK, MY, AG.

\section{REFERENCES}

1. Elsheikh M, Dunger DB, Conway GS, Wass JA. Turner's syndrome in adulthood. Endocr Rev 2002;23:120-40. [CrossRef]

2. Gravholt $\mathrm{CH}$. Epidemiological, endocrine and metabolic features in Turner syndrome. Eur J Endocrinol 2004;151:657-87. [CrossRef]

3. Gravholt CH, Juul S, Naeraa RW, Hansen J. Morbidity in Turner syndrome. J Clin Epidemiol 1998;51:147-58. [CrossRef]

4. Stochholm K, Juul S, Juel K, Naeraa RW, Gravholt CH. Prevalence, incidence, diagnostic delay, and mortality in Turner syndrome. J Clin Endocrinol Metab 2006;91:3897-902. [CrossRef]

5. Sybert VP, McCauley E. Turner's syndrome. N Engl J Med 2004;351:1227-38. [CrossRef]

6. Massa G, Verlinde F, De Schepper J, Thomas M, Bourguignon JP, Craen $\mathrm{M}$, et al; Belgian Study Group for Paediatric Endocrinology. Trends in age at diagnosis of Turner syndrome. Arch Dis Child 2005;90:267-8.

7. Apperley L, Das U, Ramakrishnan R, Dharmaraj P, Blair J, Didi M, et 
al. Mode of clinical presentation and delayed diagnosis of Turner syndrome: a single Centre UK study. Int J Pediatr Endocrinol 2018;2018:4.

8. Bucerzan S, Miclea D, Popp R, Alkhzouz C, Lazea C, Pop IV, et al. Clinical and genetic characteristics in a group of 45 patients with Turner syndrome (monocentric study). Ther Clin Risk Manag 2017;13:613-22.

9. Saenger P, Wikland KA, Conway GS, Davenport M, Gravholt $\mathrm{CH}$, Hintz R, et al; Fifth International Symposium on Turner Syndrome. Recommendations for the diagnosis and management of Turner syndrome. J Clin Endocrinol Metab 2001;86:3061-9. [CrossRef]

10. Bondy CA; Turner Syndrome Study Group. Care of girls and women with Turner syndrome: a guideline of the Turner Syndrome Study Group. J Clin Endocrinol Metab 2007;92:10-25. [CrossRef]

11. Yeşilkaya E, Bereket A, Darendeliler F, Baş F, Poyrazoğlu Ş, Küçükemre Aydin B, et al. Turner syndrome and associated problems in Turkish children: a multicenter study. J Clin Res Pediatr Endocrinol 2015;7:2736. [CrossRef]

12. Bondy CA. Heart disease in Turner syndrome. Minerva Endocrinol 2007;32:245-61.

13. Gøtzsche CO, Krag-Olsen B, Nielsen J, Sørensen KE, Kristensen BO. Prevalence of cardiovascular malformations and association with karyotypes in Turner's syndrome. Arch Dis Child 1994;71:433-6. [CrossRef]

14. Bonamico M, Pasquino AM, Mariani P, Danesi HM, Culasso F, Mazzanti L, et al; Italian Society Of Pediatric Gastroenterology Hepatology (SIGEP); Italian Study Group for Turner Syndrom (ISGTS). Prevalence and clinical picture of celiac disease in Turner syndrome. J Clin Endocrinol Metab 2002;87:5495-8. [CrossRef]

15. Ricotti S, Petrucci L, Carenzio G, Klersy C, Calcaterra V, Larizza D, et al. Prevalence and incidence of scoliosis in Turner syndrome: a study in 49 girls followed-up for 4 years. Eur J Phys Rehabil Med 2011;47:44753.
16. Gravholt CH, Andersen NH, Conway GS, Dekkers OM, Geffner ME, Klein KO, et al; International Turner Syndrome Consensus Group. Clinical practice guidelines for the care of girls and women with Turner syndrome: proceedings from the 2016 Cincinnati International Turner Syndrome Meeting. Eur J Endocrinol 2017;177:G1-70. [CrossRef]

17. Saenger P. Turner's syndrome. N Engl J Med 1996;335:1749-54.

18. Handler MZ, Derrick KM, Lutz RE, Morrell DS, Davenport ML, Armstrong AW. Prevalence of pilomatricoma in Turner syndrome: findings from a multicenter study. JAMA Dermatol 2013;149:559-64.

19. Brazzelli V, Larizza D, Martinetti M, Martinoli S, Calcaterra V, De Silvestri A, et al. Halo nevus, rather than vitiligo, is a typical dermatologic finding of turner's syndrome: clinical, genetic, and immunogenetic study in 72 patients. J Am Acad Dermatol 2004;51:354-8. [CrossRef]

20. Zvulunov A, Wyatt DT, Laud PW, Esterly NB. Influence of genetic and environmental factors on melanocytic naevi: a lesson from Turner's syndrome. Br J Dermatol 1998;138:993-7. [CrossRef]

21. Asahina A, Uno K, Fujita H. Pustular psoriasis in a patient with Turner syndrome: profile of serum cytokine levels. Int J Dermatol 2014;53:e29-32. [CrossRef]

22. Bourguignon JP, Piérard GE, Ernould C, Heinrichs C, Craen M, Rochiccioli P, et al. Effects of human growth hormone therapy on melanocytic naevi. Lancet 1993;341:1505-6. [CrossRef]

23. Wyatt D. Melanocytic nevi in children treated with growth hormone. Pediatrics 1999;104:1045-50.

24. Dhooge IJ, De Vel E, Verhoye C, Lemmerling M, Vinck B. Otologic disease in turner syndrome. Otol Neurotol 2005;26:145-50. [CrossRef]

25. Radetti G, Mazzanti L, Paganini C, Bernasconi S, Russo G, Rigon F, et al. Frequency, clinical and laboratory features of thyroiditis in girls with Turner's syndrome. The Italian Study Group for Turner's Syndrome. Acta Paediatr 1995;84:909-12. [CrossRef] 